\title{
ArtiFacts: Richard Satterlee's Bone Saw
}

\author{
Alan J. Hawk BA
}

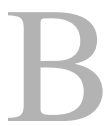

y December 1861, it had become painfully obvious that the US Civil War was going to be a long struggle, and it was equally apparent that amputation would be its signature surgical procedure. That same year, the Sanitary Commission, a private agency created during the Civil War to support sick and wounded soldiers, published a pamphlet on best practices for military medical care. "In army-practice, attempts to save a limb which might be

A note from the Editor-in-Chief:

We are pleased to present the latest installment of ArtiFacts. In this column, the Collections Manager of the Historical Collections Division of the National Museum will present a photograph of a visually or historically interesting artifact from the museum's collection, and provide the story behind the picture. Now a National Historic Landmark, the NMHM was originally developed from the Army Medical Museum, which was established during the Civil War to collect "specimens of morbid anatomy together with projectiles and foreign bodies removed"; its mission today is to inspire interest in and promote the understanding of medicine - past, present, and future - to the public.

The author certifies that neither he, nor any members of his immediate family, have any commercial associations (such as consultancies, stock ownership, equity interest, patent/licensing arrangements, etc.) perfectly successful in civil life, cannot be made... Conservative surgery is here an error; in order to save life, the limb must be sacrificed" [15].

Wartime needs forced surgeons to become familiar with amputation, a technique rarely employed before the war.

The Army procured its medical equipment at the Medical Purveyor's Office in New York City, which was commanded by surgeon Richard Satterlee [12]. He held considerable control over which pharmaceuticals, surgical instruments, and medical

that might pose a conflict of interest in connection with the submitted article. All ICMJE Conflict of Interest Forms for authors and Clinical Orthopaedics and Related Research ${ }^{\circledR}$ editors and board members are on file with the publication and can be viewed on request.

The opinions expressed are those of the writers, and do not reflect the opinion or policy of $C O R R^{\mathbb{R}}$ or The Association of Bone and Joint Surgeons ${ }^{\circledR}$.

The opinions or assertions herein are those of the author and do not represent the views of the Department of the Army, Navy or Air Force or of the Department of Defense.

\section{A. J. Hawk BA ( $\square)$}

Historical Collections, National Museum of Health and Medicine, Defense Health Agency, 2460 Linden La., Silver Spring, MD 20910, USA

e-mail: alan.j.hawk.civ@mail.mil devices the Army purchased, including specifications defining instruments contained within surgical kits [11].

Of the 4900 surgical kits purchased through the Medical Purveyor's Office [4], many were from George Tiemann \& Co, which at the time was the largest surgical-instrument manufacturer in the United States. Founded in 1826, George Tiemann \& Co was known for developing instruments easily manipulated by the surgeon, and refining the configuration of surgical kits based on input from prominent surgeons [4].

George Tiemann \& Co also had a reputation for creating innovative surgical instruments. One such instrument was an amputation saw with a pistolgrip handle, designed by Edward Pfarre [5], an instrument maker and partner in the company. Many of the smaller surgical kits included a backsaw with the Pfarre handle (Fig. 1A). This design was marketed under a variety of names after the war until it became widely identified as "Satterlee's Saw". The curious thing about the Satterlee Saw was that it was neither designed by Satterlee nor specified by him. The saw, marketed by Tiemann as "Pfarre's Amputating Saw" in 1872 [5], was described as "Satterlee's Capital Saw" 5 years later [4], 


\section{ArtiFacts}

suggesting that the latter was already colloquial.

Why did the Satterlee Saw become a quintessentially American orthopaedic saw? More than 12,000 physicians and 5532 civilian contract surgeons served with the Army during the war [1], and many developed their surgical skills using this style of saw. For example, surgeon J.W. Lyman and his two surgical assistants, performed 53 amputations during the Battle of Gettysburg from the evening of July 3, 1863 into the next morning [16]. To put that in perspective, Lyman's 53 amputations nearly equaled the 55 amputations performed by Bellevue Hospital in New York City between 1864 and 1869 [8].

By the late 19th century, surgicalinstrument manufacturers began adapting to the new aseptic procedures by designing all-metal instruments. Asepsis helped prevent infection, thus reducing the need for amputation. Charles Truax, a surgical-instruments manufacturer, observed that since the

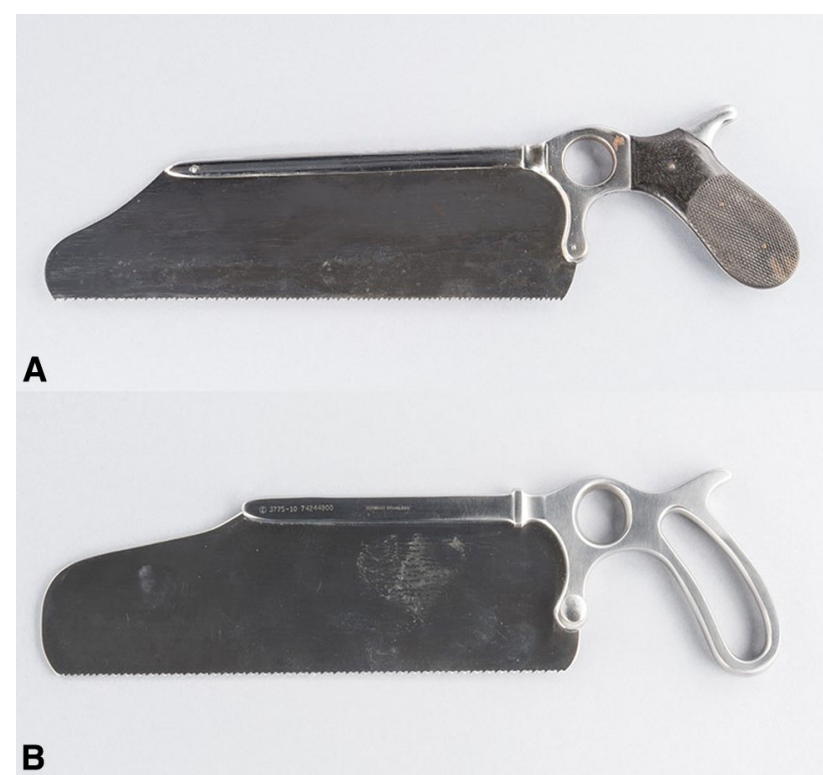

Fig. 1A-B (A) The Satterlee Capital Saw manufactured by George Tiemann \& Co. of New York during the Civil War is remarkably similar to (B) the Satterlee Bone Saw manufactured by Zimmer Inc (Warsaw, IN, USA) in 1991. Disclosure: These images have been cropped to emphasize the subject. (National Museum of Health and Medicine photos by Matthew Breitbart). 


\section{ArtiFacts}

the deck of the USS Kitty Hawk, injuring a sailor seriously enough to warrant amputation, it was one of the instruments readied for the surgical team, since “... the Satterlee Bone Saw needs to be available in case the power saw fails" [3]. More than 150 years after it was developed, the "Saw, Amputating, Satterlee" (Fig. 1B) remains standard issue within the Department of Defense, and continues to be issued to US Army hospitals within the combat zone, including on Forward Surgical Teams (in the early years of the War on Terrorism), and Combat Support Hospitals.

This year, the George Tiemann \& Co. marketed the Satterlee Saw on its website for USD 297.52 [6]. In 1872, it sold for USD 5.00.

Money well spent.

\section{References}

1. Bollet AJ. Civil War Medicine: Challenges and Triumphs. Tuscon, AZ: Galen Press; 2002:148.

2. Council of National Defense. List of Staple Medical and Surgical Supplies. Washington DC: Government Printing Office; 1918:3.

3. Dietsch D. Mass casualty on deck. The Surgical Technologist. Available at: http://www.ast.org/articles/2011/ 2011-11-335.pdf. Accessed June 20, 2017.

4. Edmondson J, Hambrecht F. George Tiemann \& Company, the American armamentarium chirurgicum and the American surgical instrument trade. In: George Tiemann \& Co., American Armamentarium Chirurgicum [reprint]. San Francisco, CA: Norman Publishing and The Printer's Devil; 1989:17-18.

5. George Tiemann \& Co. Catalogue of Surgical Instruments, Manufactured and Sold by Geo. Tiemann \& Co. New York, NY: Henry Ludwig, printer; 1872:2, 51.

6. George Tiemann \& Co. Main menu: Saws. Available at: https://www.geo rgetiemann.com/layout.asp?include =browse $\&$ cat $1=2383 \&$ cat $2=40540$. Accessed June 20, 2017.

7. Gerber F. Employment of the 307th medical battalion (Airborne) in operations desert shield and desert storm: A personal experience monograph. An individual study project at the U.S. Army War College, Carlisle Barracks, Pennsylvania 17013. Available at: http://www. dtic.mil/dtic/tr/fulltext/u2/a251837.pdf. Accessed June 20, 2017.

8. Helmuth W. A System of Surgery. New York, NY: Boericke \& Tafel; 1879:365.

9. Norway's Health and Life. Satterlee bone saw history. Available at: http:// helse.010fl.com/no/helse/201307/1716 49.html. Accessed June 20, 2017.
10. Office of the Surgeon General, U.S. Army. The Medical Department of the United States Army in the World War. Vol XI, Surgery. Washington DC: Government Printing Office; 602-651.

11. Palen JM. Richard Sherwood Satterlee, Brevet Brigadier General, U. S. Army. The Army Medical Bulletin. January 1939.

12. Smart C. Medical and Surgical History of the War of the Rebellion Part III. Volume I: Medical History. Washington DC: Government Printing Office; 1888:964-965.

13. Truax C. The Mechanics of Surgery; Comprising Detailed Descriptions, Illustrations, and Lists of the Instruments, Appliances, And Furniture Necessary In Modern Surgical Art. Chicago, IL: Hammond Press, W.B. Conkey Co; 1899:376.

14. United States Army Medical Department. Medical Department Supply Catalog. Washington, DC; Government Printing Office: 1942: 137.

15. U.S. Sanitary Commission. Report of a Committee of the Associate Medical Members of the Sanitary Commission on the Subject of Amputations. Boston, MA; David Clapp: 1861:7.

16. Woodward J, Otis G. The Medical and Surgical History of the War of the Rebellion, Appendix to Part 1. Washington DC: Government Printing Office; 1870:147. 